\title{
MENENTUKAN JENIS PENYAKIT MENGGUNAKAN METODE MAMDANI DENGAN GOLONGAN OBAT YANG SESUAI
}

\author{
Jasri \\ Fakultas Teknik, Universitas Islam Kuantan Singingi \\ Jl. Gatot Subroto KM.7 Jake teluk Kuantan Riau \\ jasri.skom@gmail.com
}

\begin{abstract}
Abstrak
Hipertensi adalah nama lain dari tekanan darah tinggi serta hipertensi bisa di artikan kondisi di mana tekanan darah lebih tinggi dari 140/90 milimeter merkuri (mmHG). Angka $140 \mathrm{mmHG}$ merujuk pada bacaan sistolik, ketika jantung memompa darah ke seluruh tubuh. Sementara itu, angka 90 mmHG mengacu pada bacaan diastolik, ketika jantung dalam keadaan rileks sembari mengisi ulang bilik-biliknya dengan darah. Fyzzy logic dengan metode mamdani adlah suatu metode untuk menentukan obt yang sesuai dengan jenis hipertensi agar hipertensi agar tetap berjalan normal.
\end{abstract}

Kata kunci: Mamdani, Obat, Hipertensi

\section{Abstrak}

Hypertension is another name for high blood pressure and hypertension can be defined as conditions in which blood pressure is higher than 140/90 millimeters of mercury (mmHG). The figure of 140 $m m H G$ refers to systolic reading, when the heart pumps blood throughout the body. Meanwhile, the figure of $90 \mathrm{mmHG}$ refers to diastolic reading, when the heart is relaxed while refilling its chambers with blood. Fyzzy logic with mamdani method is a method for determining obt that is suitable for the type of hypertension so that hypertension keeps running normally.

Keyword: Mamdani, Drug , Hypertension 


\section{PENDAHULUAN}

Resiko Hipertensi di Indonesia termasuk tinggi, perubahan gaya hidup menyebabkan peningkatan prevalensi Hipertensi, pola diet dan kebiasaan berolahraga dapat rnenstabilkan tekanan darah. Karena tidak menghindari dan tidak mengetahui faktor risiko Hipertensi, sehingga mereka cenderung untuk menjadi hipertensi berat, sebanyak 50\% di antara orang dewasa yang menderita hipertensi tidak menyadari sebagai penderita hipertensi

Penyakit hipertensi adalah peningkatan abnormaltekanan darah,baiktekanan darahsistolik maupun tekanan darah diastolik, secara umum seseorang dikatakan menderita hipertensi jika tekanan darah sistolik/diastolik $>140 / 90 \mathrm{mmHg}$ (normalnya 120/80 $\mathrm{mmHg}$ ). Penyakit hipertensi di Indonesia akan terus mengalami kenaikan insiden dan prevalensi, berkaitan erat dengan perubahan gaya hidup,mengkonsumsimakanantinggi lernak, kolesterol, penurunan aktivitas fisik, kenaikan kejadianstresdanlain-lain (Herwati, 2014).

Penentuan jenis golongan obat yang sesuai agar tekanan hipertansi tetap terkontrol maka, peneliti ingin menerapkan sebuah metode yang akan digunakan adalah metode mamdani dengan menerapakan variable-variable yang ada agar tekanan hipertensi tetap dalam keadaan normal .

Dari permaslahan yang ada peneliti mencoba agar membuat penelitan dengan judul "menentukan jenis penyakit menggunakan metode mamdani dengan golongan obata yang sesuai".

\section{TINJAUAN PUSTAKA}

\subsection{Logika Fuzzy}

Menurut ( Edy Fictor Haryanto, 2015) Metode Mamdani sering juga dikenal dengan nama Metode Max-Min. Metode ini diperkenalkan oleh Ebrahim Mamdani pada tahun 1975.Untuk mendapatkan output, diperlukan 4 tahapan:

2.1.1 Pembentukan himpunan fuzzy. Pada proses fuzzifikasi langkah yang pertama adalah menentukan variable fuzzy dan himpunan fuzzinya. Kemudian tentukan derajat kesepadanan (degree of match) antara data masukan fuzzy dengan himpunan fuzzy yang telah didefenisikan untuk setiap variabel masukan sistem dari setiap aturan fuzzy. Pada metode mamdani, baik variabel input maupun variabel output dibagi menjadi satu atau lebih himpunan fuzzy.

2.1.2 Aplikasi fungsi implikasi pada metode mamdani. Fungsi implikasi yang digunakan adalah min. Lakukan implikasi fuzzy berdasar pada kuat penyulutan dan himpunan fuzzy terdefinisi untuk setiap variabel keluaran di dalam bagian konsekuensi dari setiap aturan. Hasil implikasi fuzzy dari setiap aturan ini kemudian digabungkan untuk menghasilkan keluaran infrensi fuzzy.

2.1.3 Komposisi Aturan. Tidak seperti penalaran monoton, apabila sistem terdiri dari beberapa aturan, maka infrensi diperoleh dari kumpulan dan korelasi antar 
aturan. Ada 3 metode yang digunakan dalam melakukan inferensi sistem fuzzy, yaitu: max, additive dan probabilistik OR.

2.1.4 Penegasan (defuzzy). Input dari proses defuzzifikasi adalah suatu himpunan fuzzy yang diperoleh dari komposisi aturan-aturan fuzzy, sedangkan output yang dihasilkan merupakan suatu bilangan pada domain himpunan fuzzy tersebut

\section{1) 2.1.1 Fungsi Keanggotaan fuzzy Logic}

Menurut ( Fauzan Maskur pada jurnal Uniks, 2017 ) Funggsi keanggotaan fuzzy Logic adalah Representasi bentuk kurva membership function dapat dibagi sebagai berikut.

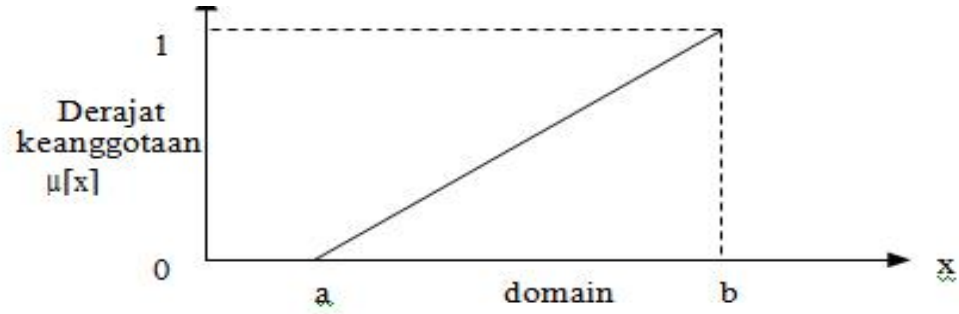

Gambar 2.1 Representasi Linier Naik

Fungsi keanggotaan:

$$
\mu[\mathrm{x}]= \begin{cases}0 ; & \mathrm{x} \leq \mathrm{a} \\ (\mathrm{x}-\mathrm{a}) /(\mathrm{b}-\mathrm{a}) ; & \mathrm{a} \leq \mathrm{x} \leq \mathrm{b} \\ A=\pi r^{\wedge} 21 ; & \mathrm{x} \geq \mathrm{b}\end{cases}
$$

Kedua, merupakan kebalikan yang pertama. Garis lurus dimulai dari nilai dominan dengan derajat keanggotaan tertinggi pada sisi kiri, kemudian bergerak menurun ke nilai dominan yang memiliki derajat keanggotaan lebih rendah. Perhatikan Gambar 2.2.

1. Representasi linear Turun

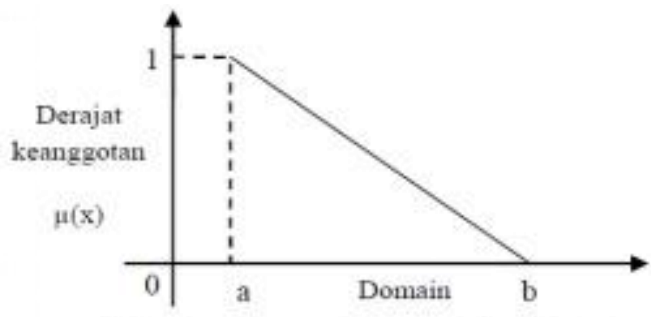

Gambar 2.2 Representasi Linear Turun

Fungsi Keanggotaan :

$\mu[x]=\left\{\begin{array}{rc}\frac{(b-x)}{(b-a)} ; & a \leq x \leq b \\ 0 ; & x \geq b\end{array}\right.$ 
2. Representasi Kurva Segitiga

Kurva Segitiga pada dasarnya merupakan gabungan antara 2 garis (linier). Perhatikan Gambar 2.3.

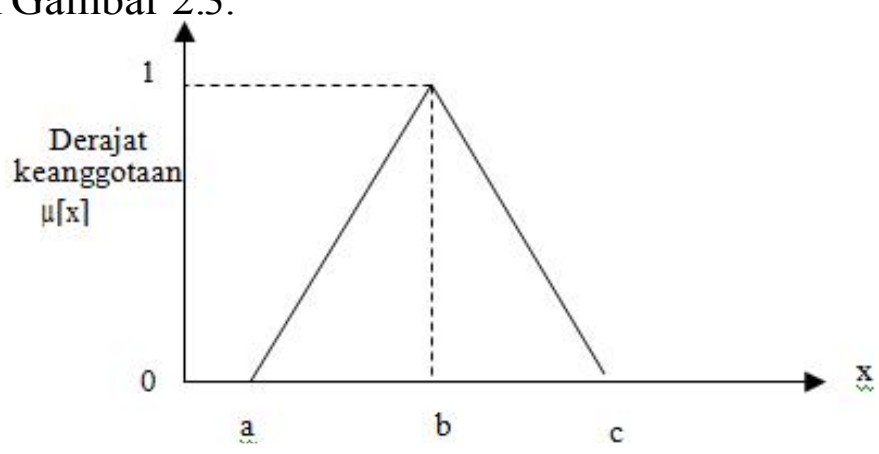

Gambar 2.3 Kurva Segitiga

Fungsi Keanggotaan

$$
\mu(x ; a, b, c)=\left\{\begin{array}{cc}
0 & x<a \\
\frac{x-a}{b-a} & a \leq x \leq b \\
\frac{c-x}{c-b} & b<x \leq c \\
1 & x>c
\end{array}\right.
$$

3. Representasi Kurva Trapesium

Kurva Segitiga pada dasarnya seperti bentuk segitiga, hanya saja ada beberapa titik yang memiliki nilai keanggotaan 1. Perhatikan Gambar 2.4.

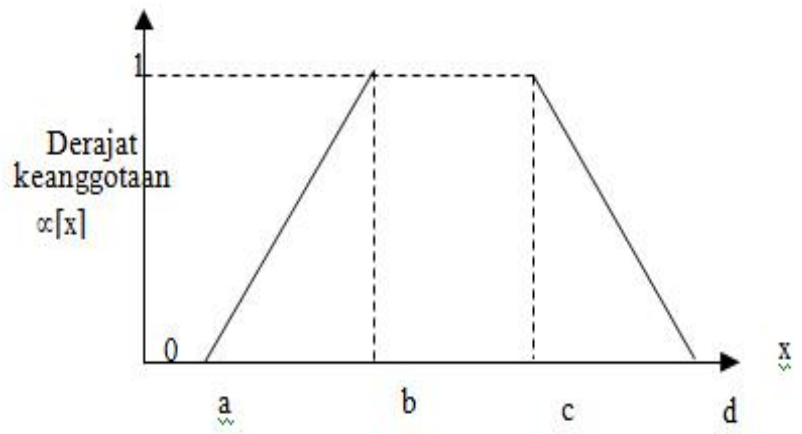

Gambar 2.4 Kurva Trapesium

Fungsi Keanggotaan:

$$
\mu[\mathrm{x}]= \begin{cases}0 ; & \mathrm{x} \leq \mathrm{a} \text { atau } \mathrm{x} \geq \mathrm{d} \\ (\mathrm{x}-\mathrm{a})(\mathrm{b}-\mathrm{a}) ; & \mathrm{a} \leq \mathrm{x} \leq \mathrm{b} \\ 1 ; & \mathrm{b} \leq \mathrm{x} \leq \mathrm{c} \\ (\mathrm{d}-\mathrm{x})(\mathrm{d}-\mathrm{c}) ; & \mathrm{c} \leq \mathrm{x} \leq \mathrm{d}\end{cases}
$$


4. Representasi Kurva Bentuk Bahu

Daerah yang terletak di tengah-tengah suatu variabel yang direpresentasikan dalam bentuk segitiga, pada sisi kanan dan kirinya akan naik dan turun (misalkan: DINGIN bergerak ke SEJUK bergerak ke HANGAT dan bergerak ke PANAS). Tetapi terkadang salah satu sisi dai variabel tersebut tidak mengalami perubahan. Sebagai contoh, apabila telah mencapai puncak kondisi PANAS, kenaikan temperatur akan tetap berada pada kondisi PANAS. Himpunan fuzzy bahu, bukan segitiga, digunakan untuk mengakhiri variabel suatu daerah fuzzy.

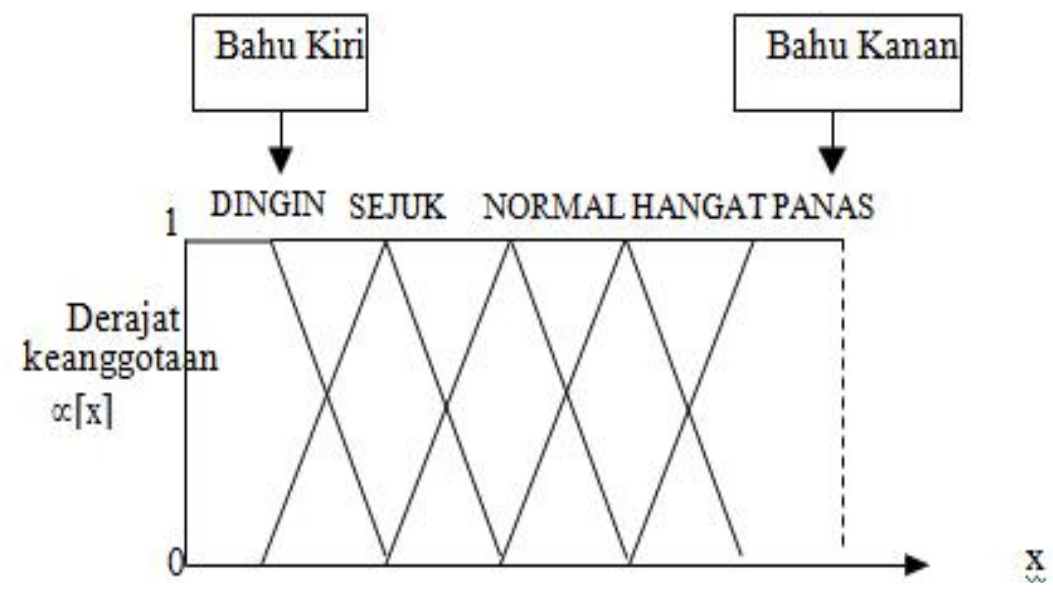

Gambar 2.5 Daerah ‘Bahu’ Pada Variabel Temperatur

5. Representasi Kurva-S

Kurva PERTUMBUHAN dan PENYUSUTAN merupakan kurva-S atau sigmoid yang berhubungan dengan kenaikan dan penurunan permukaan secara tak linier.Kurva-S untuk PERTUMBUHAN akan bergerak dari sisi paling kiri (nilai keanggotaan=0) ke sisi paling kanan (nilai keanggotaan=1). Fungsi keanggotaannya akan tertumpu pada $50 \%$ nilai keanggotaannya yang sering disebut dengan titik infleksi. Perhatikan Gambar 2.6. 


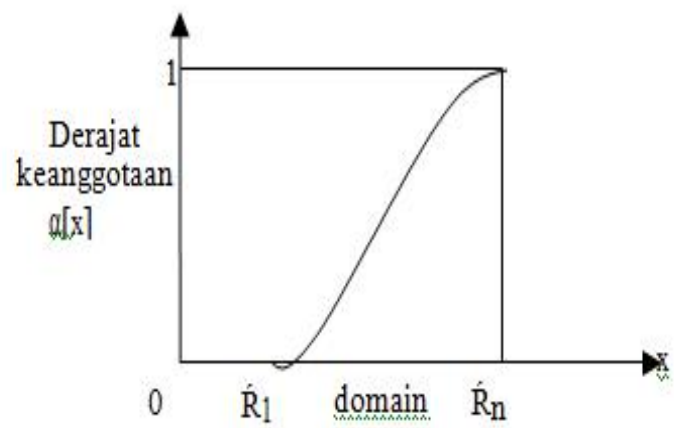

Gambar 2.6 Himpunan Fuzzy Dengan Kurva-S: PERTUMBUHAN

Kurva-S untuk PENYUSUTAN akan bergerak dari sisi paling kanan (nilai keanggotaan=1) ke sisi paling kiri (nilai keanggotaan=0). Perhatikan Gambar 2.7.

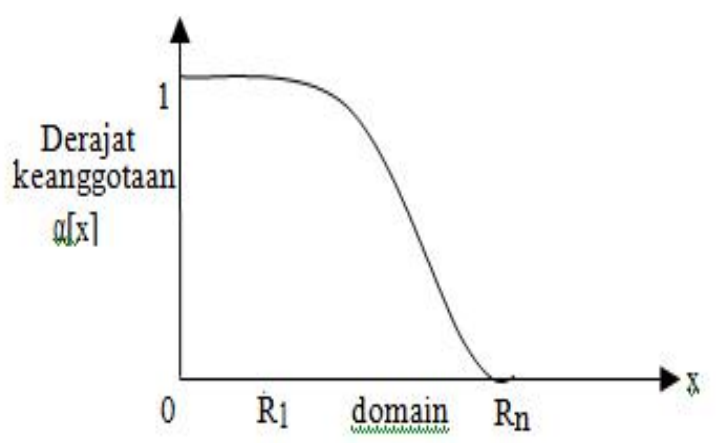

Gambar 2.7 Himpunan Kurva-s: Penyusutan

Kurva-S didefinisikan dengan menggunakan 3 parameter, yaitu: nilai keanggotaan nol $(\alpha)$, nilai keanggotaan lengkap $(\gamma)$, dan titik infleksi atau crossover $(\beta)$ yaitu titik yang memiliki domain 50\% benar. Gambar 2.8 menunjukkan karakteristik kurva-S dalam bentuk skema.

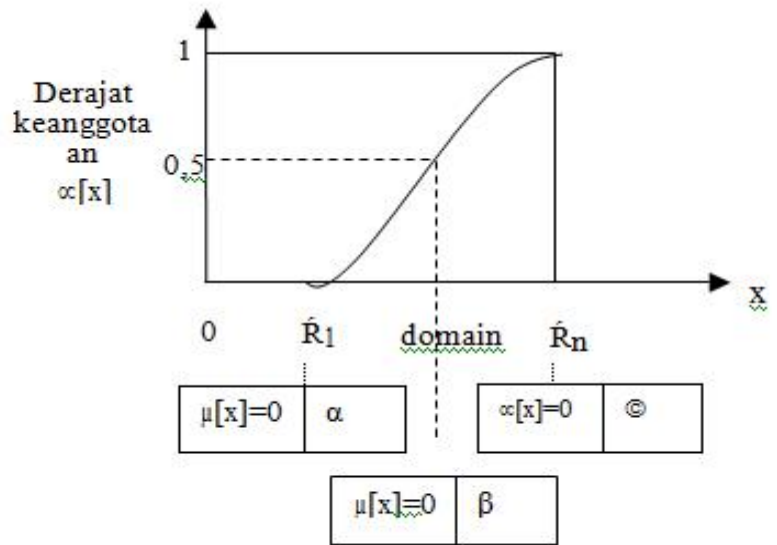

Gambar 2,8 Karakteristik Fungsi Kurva-S 
Fungsi keanggotaan pada kurva PERTUMBUHAN adalah:

$$
\mathrm{S}(\mathrm{x} ; \alpha, \beta, \gamma)= \begin{cases}0 & x \leq \alpha \\ 2((\mathrm{x}-\alpha) /(\gamma-\alpha))^{2} & \alpha \leq x \leq \beta \\ 1-2((\gamma-\mathrm{x}) /(\gamma-\alpha))^{2} & \beta \leq x \leq \gamma \\ 1 & x \geq \gamma\end{cases}
$$

Sedangkan fungsi keanggotaan pada kurva PENYUSUTAN adalah:

$$
\mathrm{S}(\mathrm{x} ; \alpha, \beta, \gamma)= \begin{cases}1 & x \leq \alpha \\ 1-2((\mathrm{x}-\alpha) /(\gamma-\alpha))^{2} & \alpha \leq x \leq \beta \\ 2((\gamma-\mathrm{x}) /(\gamma-\alpha))^{2} & \beta \leq x \leq \gamma \\ 0 & x \geq \gamma\end{cases}
$$

6. $\quad$ Representasi Kurva Bentuk Lonceng (Bell Curve)

a) Kurva PI

Kurva Pi berbentuk Lonceng dengan derajat keanggotaan 1 terletak pada pusat dengan domain $(\gamma)$, dan lebar kurva $(\beta)$

Fungsi keanggotaan:

$$
S(x, \beta, \gamma)= \begin{cases}S(x ; \gamma-\beta, \gamma-\beta / 2, \gamma) & x \leq \gamma \\ 1-S(x ; \gamma, \gamma+\beta / 2, \gamma+\beta) & x>\gamma\end{cases}
$$

Fungsi keanggotaan:

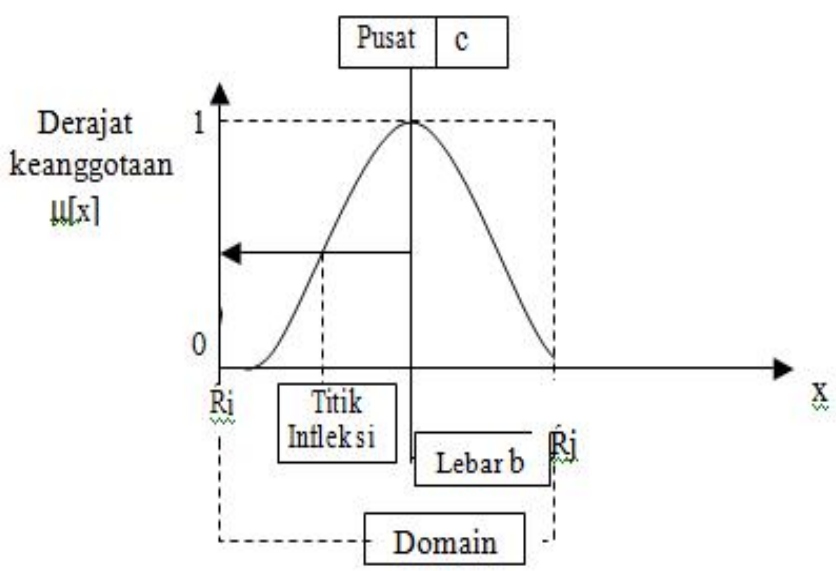

Gambar 2, 9 Karakteristik Fungsional Kurva PI. 
b) Kurva BETA

Pada kurva BETA, derajat keanggotaan 1 juga terletak pada pusat domain (c), mempunyai setengah lebar kurva (b), dan infleksi terletak pada $(c-b)$ dan $(c+b)$.

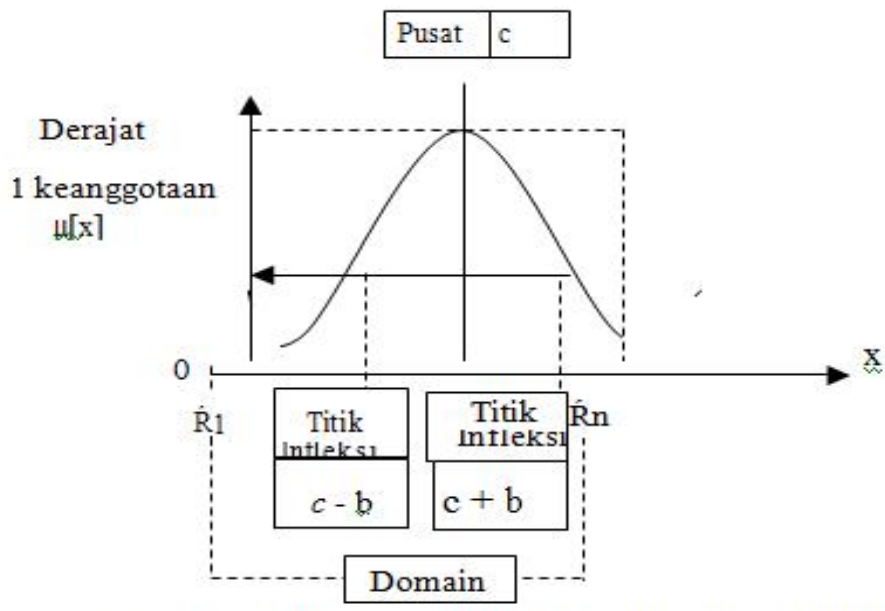

Gambar 2.10 Karakteristik Fungsional Kurva BETA

c) Kurva GAUSS

Jika kurva PI dan kurva BETA menggunakan 2 parameter yaitu $(\gamma)$ dan $(\beta)$, kurva GAUSS juga menggunakan $(\gamma)$ untuk menunjukkan nilai domain pada pusat kurva, dan (k) yang menunjukkan lebar kurva.

Fungsi keanggotaan:

$$
\mathrm{G}\left(\mathrm{x}_{\mathrm{i}} \mathrm{k}_{0} \gamma\right)=\mathrm{e}^{-\mathrm{k}(\gamma-\mathrm{x})}
$$

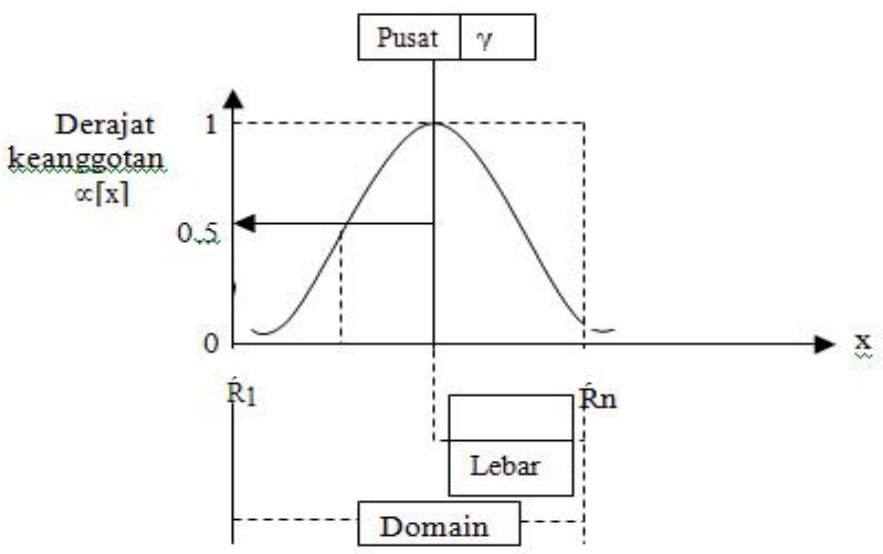

Gambar 2.11. Karakteristik Fungsional Kurva GAUS 


\section{METODE PENELITIAN}

\subsection{KERANGKA KERJA}

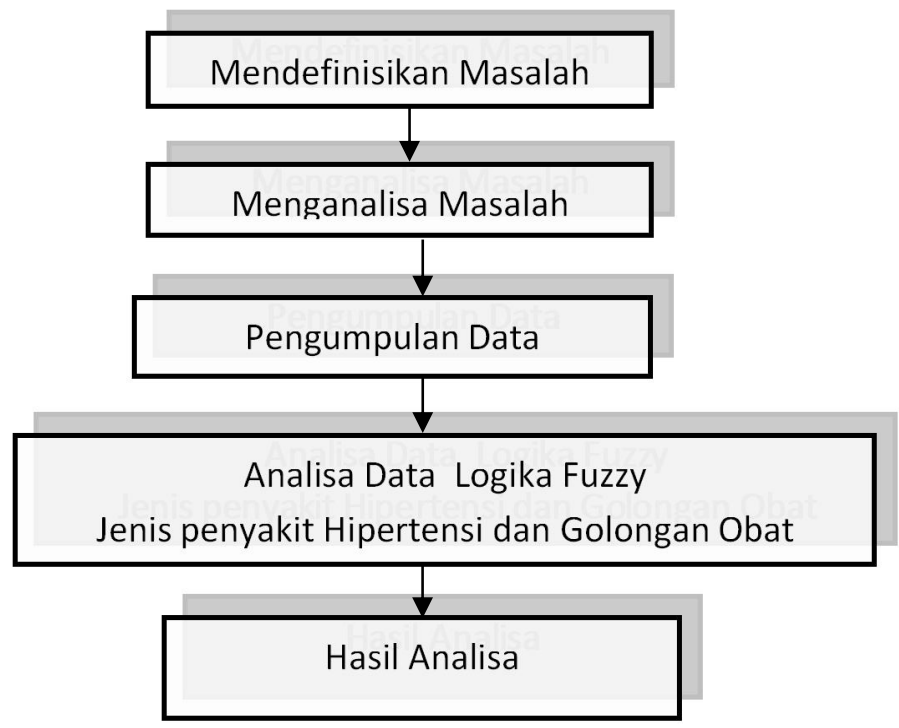

Gambar 3.1 Kerangka Kerja

Berdasarkan kerangka kerja diatas pada gambar

3.1.1 Pendefenisian Masalah Pada tahap ini dilakukan peninjauan pada masalah yang akan diteliti untuk mengamati dan melakukan eksploitasi dan mengkaji lebih dalam tentang permasalahan yang ada pada.

3.1.2 Analisa Masalah Analisa masalah dilakukan untuk menguraikan masalah-masalah yang terdapat pada penentuan penyakit masalah.

3.1.3 Pengumpulan Data Pengumpulan data yang dilakukan peneliti ada beberapa tahap seperti di bawah ini:

a. Observasi Melakukan pengamatan langsung di tempat penelitian.

b. Interview Dilakukan untuk memperoleh informasi atau data yang dibutuhkan dengan cara melakukan wawancara langsung,

c. Studi Literatur Dalam metode ini informasi dikumpulkan dengan membaca jurnal dan buku-buku yang berhubungan dengan penelitian

3.1.4 Analis Data Logika Fuzzy Jenis Penyakit Hipertensi Dan Golongan Obat Langkah menganalisa masalah adalah langkah untuk dapat memahami masalah yang telah ditentukan dalam ruang lingkup atau batasannya.

\subsubsection{Hasil Analisa}

Berdasarkan hasil dengan menerapkan Variabel-Variabel maka di temukan golongan obat dengan golongan penyakit hipertensi 


\section{HASIL DAN PEMBAHASAN}

Berdasarkan permaslahan yang ada maka dapat kita ketahui sebagai berikut :

Tabel 3.1 Himpunan Input Fuzzy

\begin{tabular}{|c|c|c|c|c|}
\hline \multicolumn{2}{|c|}{ Variabel } & \multicolumn{3}{c|}{ Himpunan Input Fuzzy } \\
\hline Nama & Notasi & Nama & Notasi & Domain \\
\hline \multirow{3}{*}{ Hipertensi } & \multirow{3}{*}{$\mathrm{A}$} & Normal & $\mathrm{N}$ & {$[70-79]$} \\
\cline { 3 - 5 } & & Prehipertensi & $\mathrm{P}$ & {$[80-89]$} \\
\cline { 3 - 5 } & Hipertensi1 & $\mathrm{H} 1$ & {$[90-99]$} \\
\cline { 3 - 5 } & Hipertensi2 & $\mathrm{H} 2$ & {$[100-120]$} \\
\hline
\end{tabular}

Tabel 3.2 Himpunan Output Fuzzy

\begin{tabular}{|c|c|c|c|c|}
\hline \multicolumn{2}{|c|}{ Variabel } & \multicolumn{3}{c|}{ Himpunan Input Fuzzy } \\
\hline Nama & Notasi & Nama & Notasi & Domain \\
\hline \multirow{3}{*}{$\begin{array}{c}\text { Golongan } \\
\text { Obat }\end{array}$} & \multirow{3}{*}{$\mathrm{B}$} & $\mathrm{Ace}$ & $\mathrm{Ae}$ & {$[70-79]$} \\
\cline { 3 - 5 } & & $\mathrm{Arb}$ & $\mathrm{Ab}$ & {$[80-89]$} \\
\cline { 3 - 5 } & & Diuretik & $\mathrm{Dr}$ & {$[90-99]$} \\
\cline { 3 - 5 } & $\mathrm{Ccb}$ & $\mathrm{Cb}$ & {$[100-120]$} \\
\hline
\end{tabular}

\subsection{Keanggotaan Fuzy Logic}

Keanggotaan Input Fuzzy Logic

Keanggotaan tekanan hipertensi

$$
\begin{aligned}
\mu_{n}(a)= \begin{cases}0 & ; a<70 \text { atau } a>79 \\
(a-74.5) / 79-0 & ; a \leq a \leq 74.5 \\
(74.5-1) / 74.5 & ; 70 \leq a \leq 79\end{cases} \\
\mu_{p h}(a)=\left\{\begin{array}{cc}
0 & ; a<80 \text { atau } a>89 \\
(a-84,5) /(84,5-80) & ; 80 \leq a \leq 84,5 \\
(89-a) /(89-84,5) & ; 84,5 \leq a \leq 89
\end{array}\right. \\
\mu_{h 1}(a)=\left\{\begin{array}{cc}
0 & ; a<90 \text { atau } a>99 \\
(a-90) /(94,5-90) & ; 90 \leq a \leq 94,5 \\
(99-a) /(99-94,5) & ; 94,5 \leq a \leq 99
\end{array}\right. \\
\mu_{h 2}(a)=\left\{\begin{array}{cc}
0 & ; a<100 \text { atau } a>120 \\
(a-100) /(110-100) & ; 100 \leq a \leq 110 \\
(120-a) /(120-110) & ; 110 \leq a \leq 120
\end{array}\right.
\end{aligned}
$$

Keanggotaan Output Fuzzy Logic

Keanggotaan Golongan Obat

$$
\mu_{a e}(b)=\left\{\begin{array}{cl}
0 & ; b<70 \text { atau } b>79 \\
(b-74.5) / 79-70 & ; b \leq d \leq 74.5 \\
(74.5-1) / 74.5 & ; 70 \leq b \leq 79
\end{array}\right.
$$




$$
\begin{aligned}
& \mu_{a b}(b)=\left\{\begin{array}{cl}
0 & ; b<80 \text { atau } b>89 \\
(b-84,5) /(84,5-80) & ; 80 \leq b \leq 84,5 \\
(89-b) /(89-84,5) & ; 84,5 \leq b \leq 89
\end{array}\right. \\
& \mu_{d r}(b)=\left\{\begin{array}{cc}
0 & ; b<90 \text { atau } b>99 \\
(d-90) /(94,5-90) & ; 90 \leq b \leq 94,5 \\
(99-d) /(99-94,5) & ; 94,5 \leq b \leq 99
\end{array}\right. \\
& \mu_{c b}(a)=\left\{\begin{array}{cl}
0 & ; b<100 \text { atau } b>120 \\
(b-100) /(110-100) & ; 100 \leq b \leq 110 \\
(120-b) /(120-110) & ; 110 \leq b \leq 120
\end{array}\right.
\end{aligned}
$$

\subsection{Fuzzyfikasi}

Adapun tujuannya dalam penelitian ini berupa fuzzyfikasi yang akan dipaparkan dibawah ini:

Contoh :

Hipertensi : 82 (Prehipertensi)

$$
\begin{aligned}
82 & : 82-80 / 89-84.5 \\
& : 0.444
\end{aligned}
$$

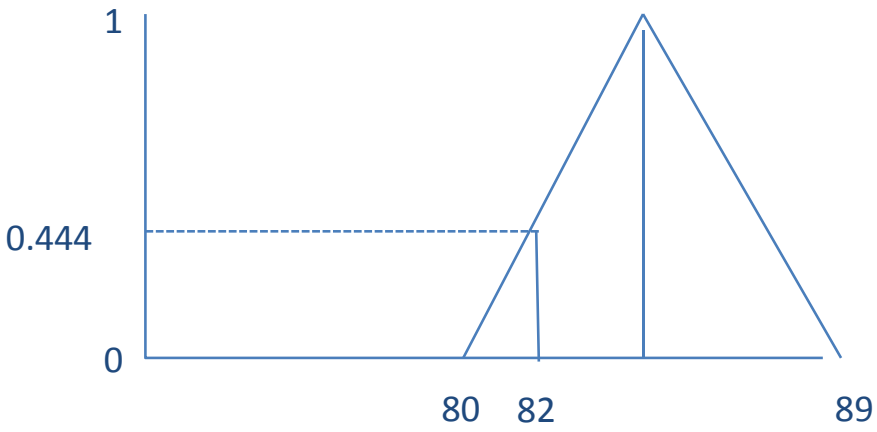

\section{Gambar 4.1 Hipertensi}

\subsection{Inference}

Inference adalah cara dalam menentuakan nilai min untuk setiap aturan yang berlaku pada

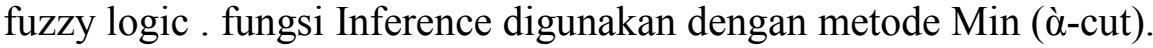

$$
\begin{aligned}
\alpha \text { prediket } & =\mu \text { Prehipertensi } \\
& =\operatorname{Min} \mu \text { Prehipertensi (82) } \\
& =\operatorname{Min}(0,444) \\
& =0,444
\end{aligned}
$$




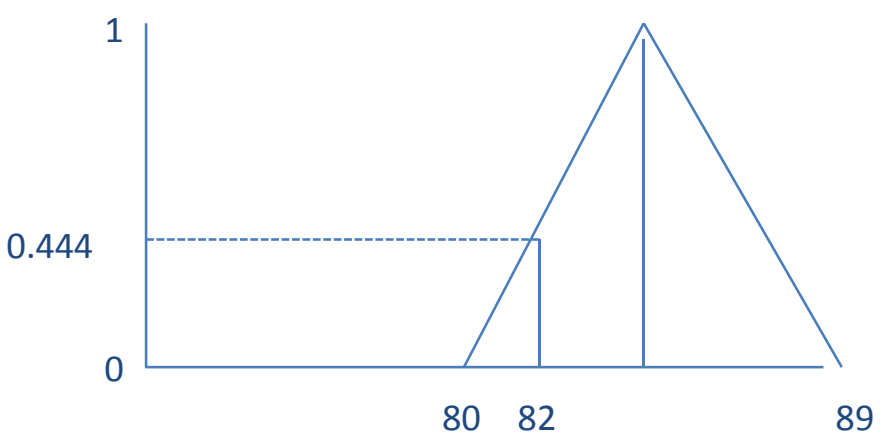

\section{Gambar 4.2 Hipertensi}

\subsection{Defuzzyfikasi}

Pada proses ini peneliti menggunakan Center Of Gravity(COG) di mana Hipertensi, dapat dirumusnya adalah rumus sebagai berikut:

$$
\begin{aligned}
& Z^{*}=\frac{\sum_{89}^{80} z j u(2 j)}{\sum_{1}^{n} u(2 j)} \\
& =\frac{80 * 0+81 * 0.444+82 * 0.444+\ldots+88 * 0.444+89 * 0}{0+(8 * 0.444)+0} \\
& =84.5
\end{aligned}
$$

\section{SIMPULAN}

Berdasarkan penelitian yang diterapkan kedalam metode mamdani untuk menentukan golongan obat yang sesuai dengan hipertensi. Jadi kesimpulan nya adalah Metode mamdani dapat menentukan golongan obat yang sesuai dengan penyakit hipertensi agar tekanan hipertensi tetap normal setelah kenggotaan fuzzy diterapkan pada Fuzzy Logic.

\section{UCAPAN TERIMAKASIH}

Alhamdulillah, puji syukur selalu peneliti panjatkan kepada Allah SWT yang telah menganugerahkan rahmat, taufik dan berkah-Nya sehingga peneliti dapat menyelesaikan dengan baik. Peneliti juga ingin menyampaikan ucapan terimakasih yang tak terhingga dan penghargaan setinggi-tingginya kepada Civitas Akademika Universitas Islam Kuantan Singingi. 


\section{DAFTAR PUSTAKA}

Jasri. (2017). "Implementasi Fuzzy Inference System dan Pareto Optimality dalam Penentuan Interaksi Obat” Jurnal UNIKS,

Herwati, dan Wiwi Sartika. (2013)." Terkontrolnya Tekanan Darah Penderita Hipertensi Berdasarkan Pola Diet dan Kebiasaan Olahraga Dipadang Tahun 2011" Jurnal KesehatanMasyarakat.

Haryanto, E, V dan Nasari , F. (2015) Penerapan Metode Fuzzy Mamdani Dalam Memprediksi Tingginya Pemakaian Listrik. Seminar Nasional Teknologi Informasi dan Multimedia.

Hanum, P. Lubis, R dan Rasmaliah. (2017).” Hubungan Karakteristik dan Keluarga Lansia dengan Kejadian Stroke Pada Lansia Hipertensi Di Rumah Sakit Umum Pusat ahji Adam Malika"Jurnal Jumantik. 